\title{
Nocturnal asthma
}

Over $80 \%$ of people with asthma experience nocturnal asthma. Cough, wheeze, and breathlessness at night are occasional problems for most asthmatic individuals ${ }^{12}$ but are regular events that interfere with the quality of life in some of those with the most severe asthma. This editorial concentrates on important recent advances in our understanding of the neurological and inflammatory mechanisms, daytime consequences, and management of nocturnal asthma.

\section{Control system}

Sleep is the main stimulus to nocturnal airway narrowing. The airways of both normal ${ }^{3}$ and asthmatic subjects narrow during sleep; the time of this narrowing changes rapidly with change of sleep time ${ }^{4}$ and the extent of overnight airway narrowing is reduced when asthmatic subjects are kept awake overnight. ${ }^{5}$ Some nocturnal airway narrowing persists during a single night of sleep deprivation $^{5}$ and thus sleep does not directly cause all of the nocturnal airway narrowing.

\section{Mechanisms}

AUTONOMIC TONE

Both cardiac ${ }^{6}$ and bronchomotor ${ }^{7}$ parasympathetic tone increase during sleep. In patients with nocturnal asthma atropinic blockade greatly decreases nocturnal airway narrowing, but does not abolish it..$^{8-10}$ Thus increased parasympathetic tone is a major factor in the pathogenesis of nocturnal asthma.

The only other direct innervation of the bronchial smooth muscle is the non-adrenergic, non-cholinergic (NANC) system, for which nitric oxide is the likely neurotransmitter. Recent evidence acquired by attempting to stimulate the NANC system with inhaled capsaicin indicates that NANC bronchodilator activity is inhibited in the early morning. ${ }^{7}$ Thus the balance of neural bronchomotor tone is swung in favour of bronchoconstriction overnight, with increased parasympathetic bronchoconstriction and decreased NANC bronchodilatation.

\section{AIRWAYS INFLAMMATION}

The suggestion that plasma histamine concentrations rise at night and cause nocturnal asthma was based on a study ${ }^{11}$ with methodological problems. ${ }^{12}$ A more recent study on larger numbers of patients with nocturnal asthma showed no rise in plasma histamine concentration despite a substantial fall in overnight peak flow. ${ }^{12}$ Considerable attention has been focused on the more direct assessment of airway inflammation by bronchoalveolar lavage and bronchial biopsy in patients with nocturnal asthma. Martin and colleagues reported an increase in total white cells, neutrophils, and eosinophils in lavage fluid at 0400 hours in comparison with 1600 hours in patients with nocturnal asthma. ${ }^{13}$ Mackay et al ${ }^{14}$ similarly found significant increases in eosinophil numbers in lavage fluid at 0400 hours in patients with nocturnal asthma and also found an increase in lymphocyte numbers, but no change in total white cell or neutrophil numbers. Jarjour et $a l^{15}$ found no change in cell numbers in lavage fluid between these two times in patients with nocturnal asthma, though only five patients were studied. Mackey et al found not only an increase in eosinophil numbers in lavage fluid but also an increase in eosinophil cationic protein in lavage fluid at 0400 hours in patients with nocturnal asthma. ${ }^{14}$ Neither Mackay et al ${ }^{14}$ nor Jarjour et $a l^{15}$ found any change in histamine concentrations in lavage fluid between the two times. Jarjour et al ${ }^{15}$ reported an early morning increase in superoxide production from lavage cells in their patients with nocturnal asthma.

These studies suggest that inflammatory activity in the airways is increased in the early morning in patients with nocturnal asthma. The trigger for this is not clear. It is tempting to invoke the sleep synchronised circadian falls in catechols and corticosteroids in the early morning. ${ }^{1617}$ Studies which have found persisting nocturnal asthma after catechol ${ }^{16}$ or corticosteroid ${ }^{17}$ replacement and after adrenalectomy ${ }^{19}$ do not prove that the falls in these are not important in the pathogenesis of the inflammatory component of nocturnal asthma-the observed persistence could reflect persisting neural bronchoconstriction. Another factor that could be implicated in the pathogenesis of the nocturnal inflammatory response is the change in autonomic tone, which will alter bronchial blood flow and possibly the permeability of the endothelium to influx of inflammatory cells into the airway.

\section{REDUCED LUNG VOLUME}

Functional residual capacity (FRC) falls during sleep. ${ }^{20} 21$ This will passively narrow the bronchial tree. Recent evidence suggests that the reduction in FRC in patients with asthma may result in bronchoconstriction that persists after awakening ${ }^{2122}$ and thus will contribute to the overnight airway narrowing seen in patients with nocturnal asthma.

\section{SNORING}

Snoring is more common in people with asthma than in the general population, ${ }^{2}$ perhaps because asthmatic patients often have rhinitis, which will increase nasal resistance and thus cause a more negative pressure to be generated in the pharynx during inspiration. There is evidence that some patients with asthma who snore loudly develop overnight airway narrowing as a direct consequence of their snoring. ${ }^{2324}$ In these patients the application of continuous positive airway pressure will substantially reduce their nocturnal airway narrowing, ${ }^{23} 24$ whether or not they have episodes of coexisting obstructive apnoea. Although a history of snoring should be sought in all patients with nocturnal asthma and appropriate treatment tried if standard measures do not suffice, in my own experience this is an unusual cause of nocturnal asthma.

Factors unimportant in the aetiology of nocturnal asthma include the supine posture, ${ }^{25}$ gastro-oesophageal reflux, ${ }^{26}{ }^{27}$ allergens in bedding, ${ }^{28}$ and increased intervals between doses of bronchodilator due to sleep. ${ }^{29}$

Thus the causes of nocturnal airway narrowing are multifactorial (figure). These factors cause nocturnal airway narrowing in everyone, whether normal or asthmatic; but, as with other stimuli, patients with asthma show a more obvious response in terms both of decrement in lung function and of symptoms. Indeed, there is a linear relationship between a subject's reactivity to histamine and the overnight decrease in peak flow, ${ }^{30}$ and thus the 
twitchier the airways the greater the overnight drop in peak flow. Similarly, any factor that will increase reactivity, such as exposure to a known allergen at whatever time of day, will increase the nocturnal drop in peak flow and may induce symptoms of nocturnal asthma. ${ }^{31}$

\section{Consequences}

ASTHMATIC ATTACKS

Most patients with asthma experience worsening of their asthma at night or in the early morning, at least from time to time. In some, however, this is a nightly occurrence, significantly impairing their own quality of life and that of their close family. Patients with asthma present to general practitioners and accident and emergency departments more frequently by night than by day, ${ }^{32}$ to the inconvenience of both the patient and the medical staff.

Ventilatory arrests in asthmatic patients are more common by night than by day, ${ }^{33}$ as are deaths from asthma. ${ }^{34}$ Although many causes may contribute to the excess of deaths at night in asthmatic patients, nocturnal airway narrowing is probably the most important.

\section{SLEEP DISRUPTION AND ITS CONSEQUENCES}

Patients with nocturnal asthma sleep poorly, with an increase in wakefulness and drowsiness during the night and a decrease in deep (slow wave) sleep. ${ }^{35}{ }^{36}$ Recent evidence indicates that asthmatic are more likely than the rest of the population to report that they get too little sleep and that they find nocturnal sleep unrefreshing. ${ }^{2}$ They may have slightly more irregular breathing at night than the general population ${ }^{35}$ but this would not be sufficient to account for their sleep related symptoms and sleep disruption, which seem more likely to be related directly to the effects of their airway narrowing. Some patients with nocturnal asthma complain of impaired work performance. Daytime cognitive function appears to be worse in patients with nocturnal asthma than in age, sex, and education matched normal subjects. ${ }^{37}$. This deficit is likely to be due to sleep disturbance, and certainly in the study of Fitzpatrick et $a^{37}$ seemed not to be due to the drugs used to treat the asthma.

\section{Treatment}

The essential element in the treatment of nocturnal asth$\mathrm{ma}$ is to regard it as a marker of inadequate control of asthma. Thus treatment must be aimed at maximising prophylaxis before specific bronchodilator treatment is introduced. Inhaled corticosteroids will reduce nocturnal asthma $^{38}$ and only if high dose inhaled steroids do not control the nocturnal asthma should long acting bronchodilators be introduced. I believe that inhaled long acting $\beta$ agonists such as salmeterol and formoterol are the current long acting bronchodilators of choice. They are effective over the whole duration of a night's sleep, ${ }^{3940}$ improve symptoms in patients with nocturnal asthma, ${ }^{4142}$ and improve overnight peak flow; ${ }^{4142}$ and at least salmeterol has been shown to improve objective sleep quality in patients with nocturnal asthma as judged by electroencephalography. ${ }^{41}$ In contrast, oral sustained release bronchodilators have a relatively high frequency of side effects and, although they may be effective bronchodilators, they do not improve objective sleep quality ${ }^{43}{ }^{44}$-indeed, theophyllines may actually impair sleep. ${ }^{43}$

\section{Conclusions}

Nocturnal worsening of cough, wheeze, and breathlessness are common problems for many patients with asthma, disrupting their sleep and impairing their daytime performance. Recent studies have identified that alterations of cholinergic and NANC function at night, in combination with increased airway inflammation, are major factors in the pathogenesis of nocturnal airway narrowing. The development of long acting inhaled bronchodilators has improved management of those patients who do not respond to standard asthma treatment.

NEIL J DOUGLAS Respiratory Medicine Unit, University of Edinburgh, City Hospital, Edinburgh, EH1O 5SB

Correspondence to: Dr N J Douglas

1 Turner-Warwick M. Nocturnal asthma: a study in general practice. $7 R$ Coll Gen Pract 1989;39:239-43.

2 Fitzpatrick MF, Martin K, Fossey E, Shapiro CM, Elton RA, Douglas NJ. Snoring, asthma and sleep disturbance in Britain: a community based survey. Eur Respir $\mathcal{f}$ (in press)

3 Kerr HD. Diurnal variation of respiratory function independent of air quality. Arch Environ Health 1973;26:144-53.

4 Hetzel MR, Clark TJH. Does sleep cause nocturnal asthma? Thorax 1979;34:749-54.

5 Catterall JR, Rhind GB, Stewart IC, Whyte KF, Shapiro CM, Douglas NJ. Effect of sleep deprivation on overnight bronchoconstriction in nocturnal asthma. Thorax 1986;41:676-80.

6 Baust W, Bohnert B. The regulation of heart rate during sleep. Exp Brain Res 1969;7:169-80.

7 MacKay TW, Fitzpatrick MF, Douglas NJ. Non-adrenergic, non-cholinergic nervous system and overnight airway calibre in asthmatic and norergic nervous system and overnight airway

8 Catterall JR, Rhind GB, Whyte KF, Shapiro CM, Douglas NJ. Is nocturnal asthma caused by changes in airway cholinergic activity? Thorax 1988;43:720-4.

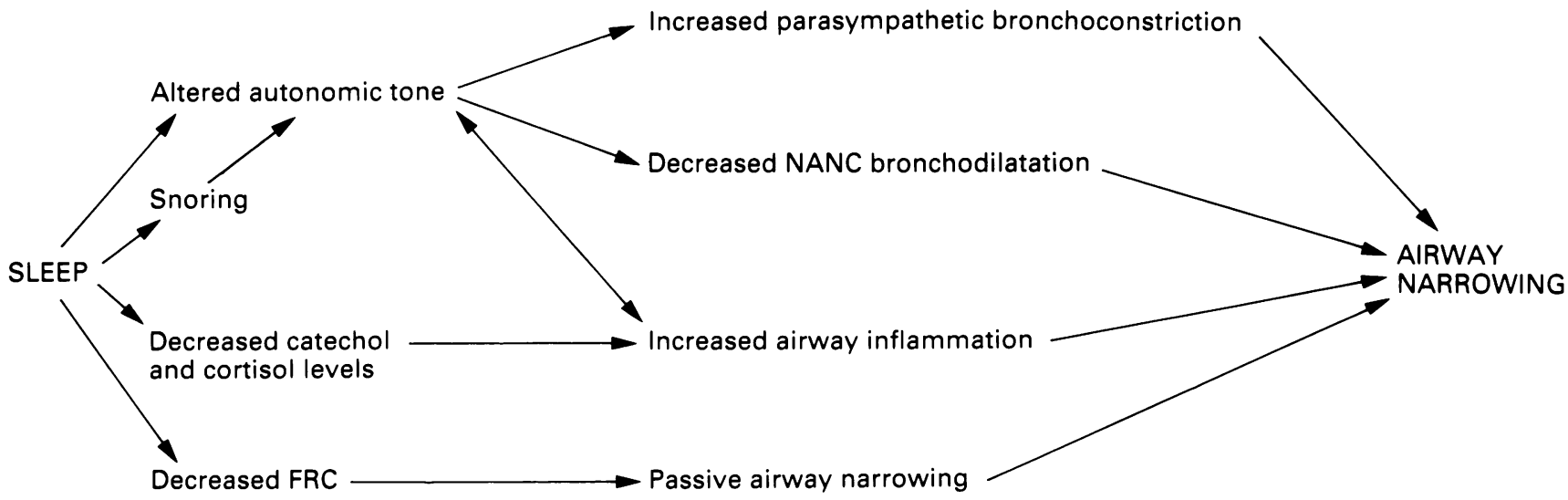


9 Morrison JFJ, Pearson SB, Dean HG. Parasympathetic nervous system in nocturnal asthma. $B M F$ 1988;296:1427-9.

10 Morrison JFJ, Pearson SB. The parasympathetic nervous system and the diurnal variation of lung mechanics in asthma. Respir Med 1991;85: 285-9.

11 Barnes PJ, Fitzgerald G, Brown M, Dollery C. Nocturnal asthma and changes in circulating epinephrine, histamine and cortisol. $N$ Engl $\mathcal{f}$ Med 1980;303:263-7.

12 Fitzpatrick MF, MacKay T, Walters C, Tai PC, Church MK, Holgate ST, et al. Circulating histamine and eosinophil cationic protein levels in nocturnal asthma. Clin Sci 1992;83:227-32

13 Martin RJ, Cicutto LC, Smith HR, Ballard RD, Szefler SJ. Airway inflammation in nocturnal asthma. Am Rev Respir Dis 1991;143:351-7.

14 MacKay TW, Brown P, Wallace W, Lamb D, Ramage E, Howie S, et al. Does inflammation play a role in nocturnal asthma? [abstract]. Am Rev Respir Dis 1992;145:A22.

15 Jariour NN, Busse WW, Calhoun WJ. Enhanced production of oxygen radicals in nocturnal asthma. Am Rev Respir Dis 1992;146:905-11.

16 Soutar CA, Carruthers M, Pickering CAC. Nocturnal asthma and urinary adrenaline in noradrenaline concentrations. Thorax 1979;32:677-83.

17 Soutar CA, Costello J, Ijaduola O. Nocturnal and morning asthma. Thorax 1975;30:436-40.

18 Morrison JFJ, Teale C, Pearson SB, Marshall P, Dwyer DMA, Jones S, et al. Adrenaline and nocturnal asthma. BMF 1990;301:473-6.

19 Morice A, Sever P, Ind P. Adrenaline, bronchoconstriction and asthma. BMF 1986;293539-40.

20 Hudgel DW, Martin RJ, Johnson B, Hill P. Mechanics of the respiratory system and breathing pattern during sleep in normal humans. F Appl Physiol 1984;56:133-7.

21 Ballard RD, Irvine CJ, Martin RJ, Pack J, Pandey R, White DP. Influence of sleep on lung volume in asthmatic patients and normal subjects. $\mathcal{F}$ Appl Physiol 1990;68:2034-41.

22 Ballard RD, Pack J, White DP. Influence of posture and sustained loss of lung volume on pulmonary function in awake asthmatic subjects. $A m$ Rev Respir Dis 1991;144:499-503.

23 Chan CS, Woolcock AJ, Sullivan CE. Nocturnal asthma: role of snoring in obstructive sleep apnea. Am Rev Respir Dis 1988;137:1502-4.

24 Guilleminault C, Quera-Salva MA, Powell N, Riley R, Romaker A Partinen $\mathrm{M}$, et al. Nocturnal asthma: snoring, small pharynx and nasal CPAP. Eur Respir $\mathcal{f}$ 1988;1:902-7.

25 Whyte KF, Douglas NJ. Posture and nocturnal asthma. Thorax 1989; 44:579-81.

26 Nadgel RA, Brown P, Perks W, Wilson RSE, Kerr GD. Ambulatory pH monitoring and gastro-eosophageal reflux in "morning dipper" asthmatics. $B M \mathcal{F} 1988 ; 297: 1371-3$.
27 Tan WC, Martin RJ, Pandy R, Ballard RD. Effect of spontaneous and simulated gastro-oesphageal reflux in sleeping asthmatics. Am Rev Respir Dis 1990;141:1394-9.

28 Clark TJH, Hetzel MR. Diurnal variation of asthma. $\mathrm{Br} f$ Dis Chest 1977;71:87-92.

29 Turner-Warwick $M$. On observing patterns of airflow obstruction in chronic asthma. Br $\mathcal{F}$ Dis Chest 1977;71:73-86.

30 Ryan G, Latimer KM, Dollovich J, Hargreave FE. Bronchial responsiveness to histamine: relationship to diurnal variation of peak flow rate, improvement after bronchodilator, and airway calibre. Thorax 1982;37: 423-9.

31 Davies RJ, Green M, Schofield NM. Recurrent nocturnal asthma after exposure to grain dust. Am Rev Respir Dis 1976;114:1011-9.

32 Horn CR, Clark TJH, Cochrane GM. Is there a circadian variation in respiratory morbidity. $\mathrm{Br} F \mathrm{D}$ is Chest 1987;81:248-51.

33 Hetzel MR, Clark TJH, Branthwaite MA. Asthma: analysis of sudden deaths and ventilatory arrests in hospital. BMF 1977;1:808-11.

34 Douglas NJ. Asthma at night. Clin Chest Med 1985;6:663-74

35 Catterall JR, Douglas NJ, Calverley PMA, Brash HM, Brezinova V, Shapiro CM, et al. Irregular breathing and hypoxaemia during sleep in chronic stable asthma. Lancet 1982;i:301-304.

36 Montplaisir J, Walsh J, Mallard JL. Nocturnal asthma: features of attacks, sleep and breathing patterns. Am Rev Respir Dis 1982;125:18-22.

37 Fitzpatrick MF, Engleman H, Whyte KF, Deary I, Shapiro CM, Douglas NJ. Morbidity in nocturnal asthma: sleep quality and daytime cognitive performance. Thorax 1991;46:569-73.

38 Horn CR, Clark TJH, Cochrane CM. Inhaled therapy reduces morning dips in asthma. Lancet 1984; i:1143-5.

39 Ullman A, Svedmyr N. Salmeterol, a new long-acting inhaled $\mathbf{B}_{2}$ adrenoceptor agonist: a comparison with salbutamol in adult athmatic patients. Thorax 1988;43:674-8.

40 Midgren B, Melander B, Persson G. Formoterol, a new long-acting $B_{2}$ agonist, inhaled twice daily, in stable asthmatic subjects. Ches 1992;101:1019-22.

41 Fitzpatrick MF, MacKay $T$, Driver $H$, Douglas NJ. Salmeterol in nocturnal asthma: a double blind, placebo controlled trial of a long acting inhaled B2 agonist. BMF 1990;301:1365-8.

42 Maesen FPV, Smeets JJ, Gubbelmans HLL, Zweers PGMA. Formotero in the treatment of nocturnal asthma. Chest 1990;98:866-70.

43 Rhind GB, Connaughton JJ, McFie J, Douglas NJ, Flenley DC. Sustained release choline theophyllinate in nocturnal asthma. $B M^{f}$ 1985;291:1605-7.

44 Stewart IC, Rhind GB, Power JT, Flenley DC, Douglas NJ. Effect of sustained release terbutaline on symptoms and sleep quality in patients with nocturnal asthma. Thorax 1987;42:797-800. 